\title{
CONFIGURAÇÕES DO ATIVISMO ANTI-AIDS NA CONTEMPORANEIDADE
}

\author{
Maio Spellman Quirino de Farias \\ Magda Dimenstein
}

\begin{abstract}
RESUMO. Este artigo tem como objetivo apresentar as investigações acerca da atual prática do ativismo anti-aids entre os técnicos vinculados ao Grupo de Apoio à Vida (GAV), na cidade de Campina Grande/PB. Outros objetivos da investigação foram: identificar as concepções de ativismo anti-aids para técnicos e conhecer como esses atores sociais avaliam essas práticas atualmente realizadas pela ONG. O favorecimento ou não da criação de novas estratégias de ativismo, através do funcionamento do GAV, também foi investigado. A pesquisa teve início com visitas à instituição, no segundo semestre de 2004, na cidade de Campina Grande-PB, onde foram realizadas entrevistas - a partir de um roteiro semi-estruturado - com seis técnicos da referida entidade. Resultados iniciais da pesquisa indicam que a nova forma de ativismo está consubstanciada na execução de projetos e na inserção da ONG nos conselhos de representação social, mas a mobilização de rua precisa ser resgatada.
\end{abstract}

Palavras-chave: ONGs/Aids, ativismo, contemporaneidade.

\section{ANTI-AIDS ACTIVISM IN THE CONTEMPORANEITY}

\begin{abstract}
This article has the objective to present the investigations concerning the current practice of anti-aids activism among the technicians linked to the Group of Support to Life (GSL), in Campina Grande, Paraiba State - Brazil. Other objectives of the investigation were: to identify the conceptions of anti-aids activism for technicians and to know how they evaluate those practices accomplished by the Non-Governmental Organization. The favoring or not on the creation of new strategies of activism, through the operation of GSL, was also investigated. The research started with visits to the institution, in the second semester of 2004, in the city of Campina Grande, where semi-structured interviews were accomplished with six volunteer technicians of the referred entity. Preliminary results indicate that the new form of activism is consubstantiated in the execution of projects and in the insertion of NOG in the social representation councils, but the street mobilization needs to be rescued.
\end{abstract}

Key words: Non-governamental organizations, activism, contemporaneity.

A luta contra a aids ${ }^{1}$ é uma manifestação em defesa da vida, e a sociedade civil organizada brasileira a incorporou numa dimensão significativa em nossos dias. Essa luta maturou a criação de organizações nãogovernamentais (ONGs) que se confundem com o avanço das descobertas sobre a doença e também com a epidemiologia relacionada à notificação dos casos. Do mesmo modo que a aids atingiu o interior do País, as ONGs/AIDS foram fundadas seguindo os rastros da doença. Para Câmara e Lima (2000), diante do crescente aumento da epidemia, foi inevitável o surgimento de ONGs com o propósito de trabalhar especificamente com aids.

Sobre o conceito de ONG/AIDS, Galvão (2000) afirma que há duas concepções para o termo. Uma delas sustenta que "ONG/AIDS" é toda e qualquer instituição que desenvolve alguma atividade relacionada à aids; a outra afirma que o termo deve ser empregado somente para organizações que trabalham exclusivamente com aids.

* Mestrando do Programa de Pós-graduação de Psicologia da UFRN e bolsista Capes.

\# Doutora em Saúde Mental pela Universidade Federal do Rio de Janeiro, é professora do Departamento de Psicologia da Universidade Federal do Rio Grande do Norte.

1 Segundo Câmara e Lima (2000), a palavra 'aids' passou a ser, do ponto de vista gramatical, equivalente a 'sífilis', 'coqueluche', 'conjuntivite'. Nomes de doenças são substantivos comuns grafados com inicial minúscula, conforme observações de Castilho (1997), a não ser quando correspondem a nomes próprios de entidades ou siglas que incorporem a palavra. Por uma questão de padronização vamos utilizar maiúsculas quando se tratar de siglas conjuntas, tipo: HIV/AIDS, ONG/AIDS, etc. 
As primeiras ONGs/AIDS do país surgiram nas metrópoles do eixo Sul/Sudeste, com perfis diversificados. O Grupo de Apoio à Prevenção à AIDS (GAPA), fundado em São Paulo, em 1985, a Associação Brasileira Interdisciplinar de AIDS (ABIA), fundada no Rio de Janeiro, em 1986, e o Grupo pela Valorização, Integridade e Dignidade do Doente de AIDS (Grupo Pela Vidda), fundado no Rio de Janeiro, em 1989, com o objetivo, tal qual o GAPA, de congregar portadores do $\mathrm{HIV}^{2}$ e fazer prevenção à aids.

A migração da doença para o interior do Brasil refletiu-se na criação de novas ONGs, fundadas além do eixo Centro-Oeste/Sul/Sudeste. Em Campina Grande-PB, foi fundado, no ano de 1994, o Grupo de Apoio à Vidda (GAV), com o objetivo de estudar uma "doença nova que surgia no cenário mundial", e para isso reunia-se numa paróquia católica da cidade. A partir da expulsão de um portador do vírus HIV, parente de um membro desse "grupo de estudo", pela direção de um hospital da cidade, fez-se a denúncia do ocorrido, os médicos e o hospital foram representados juridicamente e o GAV surgiu, oficializando-se como ONG.

Prontamente o GAV aglutinou portadores do vírus que viviam isolados em suas casas, bem como voluntários, pessoas comuns da sociedade local, entre 17 e 45 anos, para atuar na luta contra a aids. Eram donas-de-casa, estudantes secundaristas e estudantes universitários. Isso fez a entidade ter um caráter sorodiscordante $^{3}$, o que era incomum em relação a outras ONGs/AIDS do restante do Brasil, já que em sua maioria foram fundadas eminentemente por portadores do vírus.

O GAV, assim como as demais ONGs/AIDS, demarcou seu território de atuação no campo de batalha contra a epidemia da aids, transformando-se em um instrumento de luta contra preconceitos, discriminações, desinformações e omissões, objetivando combater a epidemia e suas consequiências.

Com o passar do tempo, uma ruptura se produziu: o portador do vírus da aids viu-se envolvido num ativismo institucional através do qual, em seu nome, captam-se recursos para as licitações governamentais, visando à aquisição de medicamentos. Em torno dele, consolida-se o mercado de produção, consultoria e

2 HIV: do inglês Human Imunodeficiency Vírus. Em Português: Vírus da Imunodeficiência Humana - VIH.

3 Terminologia que indica relação entre soropositivos e soronegativos, ou seja, entre pessoas portadoras e não portadoras do vírus HIV. execução de projetos, os quais mantêm as próprias ONGs. Atualmente tais organizações se configuram como estruturas que funcionam prioritariamente através do financiamento de projetos, entre cujas prioridades institucionais estão, dentre outras coisas, o financiamento do aluguel da sede e a aquisição de equipamentos eletroeletrônicos, por exemplo.

Em detrimento das conquistas do movimento creditadas ao ativismo institucional e coletivo dos portadores - traduzido, por exemplo, na distribuição gratuita de medicamentos e preservativos -, as contradições da luta manifestam-se nas novas estruturas de organizações as quais,

Apesar de continuarem sem fins lucrativos, não teriam as características que lhe valem o nome terceiro setor/ONG, sem o mercado. Sem fins lucrativos porque supõe a existência do lucro em outro plano. Não houvesse a autonomia do mercado, não haveria a autonomia das organizações sem fins lucrativos (Fernandes, 2004, p. 20).

Por mercado entenda-se portador do HIV. Ao gerenciar esse "mercado", as ONGs transformaram-se em empresas e os portadores em coadjuvantes, visto que o ativismo de rua, talvez o mais eficiente, deu lugar ao ativismo de gabinete, que motiva o portador a aderir apenas aos programas governamentais de assistência e tratamento e aos programas institucionais de consultoria e execução de projetos. Isso reflete uma instituição que agrega a relação Estado/mercado/terceiro setor. Sobre isso, Fernandes assegura que

A complementaridade entre o Estado, o mercado e o terceiro setor pode se dar ou não, pode ser mais ou menos feliz, mais ou menos eficaz. Sua sorte depende de múltiplos fatores, alguns previsíveis, outros não. Entre esses fatores de combinatória imponderável está a própria crença de que a integração é possível e desejável (Fernandes, 2004, p. 21).

$\mathrm{O}$ ativismo atual anti-aids aponta um grande paradoxo: de um lado, tem-se o portador do vírus HIV/AIDS, que é assistido pela ONG e pelos programas e vem recebendo assessoria de todos os tipos, além dos medicamentos; do outro lado há a estrutura das ONGs que não consegue dialogar e ampliar a interface portador/ONG de modo cotidiano e constante. Nesse meio, o Estado coloca-se como mediador e, com seu viés neoliberal, prioriza respostas imediatistas às necessidades que vão surgindo, sem preocupação com os seus efeitos. O exemplo maior deste fato é a fomentação da atividade voluntária, reconhecida pela Lei 9.608, de 18 de fevereiro 
de 1998, caracterizada "como atividade não remunerada prestada por pessoa física a entidade pública" (Montaño, 2003, p. 203), sem gerar vínculo empregatício.

Acredita-se que esse modo atual de ativismo ou de funcionamento institucional anti-aids tem problemas, porque constrói uma estratégia básica para despolitizar o terceiro setor. Embora estrategicamente as ONGs desenvolvam ações harmônicas, integradoras e de parcerias, em detrimento da ação política, ao mesmo tempo, mascaram o desemprego e desempenham atividades que deveriam ser públicas, como a distribuição de cestas básicas, dando-lhes um caráter privado. Além disso remercantilizam os serviços sociais, a partir do momento em que recebem verbas para a execução de projetos sociais e filantropizam as respostas às questões sociais quando vão atender à população excluída ou semi-integrada, quase nãocidadãos, que não têm acesso à saúde e aos serviços básicos de atenção (Montaño, 2003). Neste sentido, as ONGs/AIDS não apenas consolidam a reestruturação moderna do capital mas também fomentam a privatização da seguridade e das políticas sociais e assistenciais.

Todas as questões acima levantadas levaram-nos a mapear a nova estrutura Onguiana, que rompeu com o caráter caritativo, assumindo uma gestão semigovernamental, consolidada na prestação de serviços terceirizados, o que pode levá-las a "se afastar de sua agenda de mobilização política, de resistência coletiva e de intervenção, e a se voltar para a agenda dos governos e dos setores governamentais que repassam financiamentos" (Terto Júnior, 2004, online).

Com base nisso, desenvolvemos uma investigação com o objetivo de investigar as concepções e práticas de ativismo anti-aids entre os técnicos vinculados ao Grupo de Apoio à Vida (GAV), na cidade de Campina Grande - PB.

\section{OBJETIVOS E MÉTODO}

A pesquisa teve início com visitas, previamente agendadas, à instituição Grupo de Apoio à Vidda (GAV), no segundo semestre de 2004, na cidade de Campina Grande - PB. Após aprovação do GAV e do comitê de ética da UFRN, as entrevistas foram realizadas, seguindo um roteiro semi-estruturado, com os seis técnicos ${ }^{4}$ da referida entidade - quatro homens e duas mulheres.

\footnotetext{
4 "Técnico" foi definido como sendo membro participante da entidade que é remunerado por projeto e cujo grau de escolaridade é curso superior.
}

O instrumento de coleta de dados foi construído para atender ao objetivo da pesquisa, qual seja o de delinear o perfil do técnico inserido na instituição, assim como a investigação da prática do ativismo antiaids nos seguintes aspectos: identificação das concepções de ativismo anti-aids; conhecimento de como os técnicos avaliam as práticas (se ativistas ou não) atualmente realizadas pelo grupo; investigação dos aspectos do funcionamento da vida orgânica do Grupo de Apoio à Vida (GAV), relacionando-os ao favorecimento ou não da criação de novas estratégias de ações anti-aids.

Para analisar os dados obtidos através das entrevistas com técnicos, apoiamo-nos no método de análise das práticas discursivas, proposto por Spink (2000), numa abordagem qualitativa de entender e fazer pesquisa científica. A operacionalização dessa análise consiste no delineamento de categorias/temas gerais que surgem a partir dos dados das entrevistas, refletindo os objetivos da pesquisa. Depois, foi realizada uma depuração das categorias através de mapas de associação de idéias (Spink \& Lima, 2000).

Segundo Spink e Lima (2000), "os mapas têm o objetivo de sistematizar o processo de análise das práticas discursivas em busca dos aspectos formais da construção linguística, dos repertórios utilizados e da dialogia implícita na produção de sentidos" (p.107). Desse modo, os conteúdos serão organizados a partir de tais categorias, preservando a seqüência das falas e identificando os processos de interanimação dialógica a partir da visualização esquematizada da entrevista como um todo.

\section{RESULTADOS}

Em sua maioria, os técnicos possuem uma média de idade acima de 30 anos, ingressaram no GAV há mais de 04 anos e são solteiros. Dois são advogados, um é assistente social, um é psicólogo, um sociólogo e por último um é auxiliar de informática. Nenhum é portador do vírus HIV.

Os motivos apontados pelos técnicos para ingresso na instituição foram variados. Observamos entre eles o interesse pela temática da aids, questões de cunho pessoal e familiar, bem como a prática do estágio acadêmico. Um dos técnicos entrevistados citou sua experiência pessoal com um irmão que se descobrira portador do HIV e outro apontou o Programa de Bolsas de Extensão/UFPB - PROBEX - como um instrumento de ingresso na instituição em 1999.

Em relação às atividades desenvolvidas pelo grupo foram apontadas atividades assistenciais, tais 
como a entrega de cestas básicas e visitas hospitalares; atividades educativas de promoção da saúde do portador do HIV/AIDS, tais como as reuniões denominadas de chá+ e atividades de prevenção através de palestras em escolas e empresas. Foram citadas também atividades de assessoria em orientação sexual e atividade telefônica de prevenção pelo GAV/DISK-AIDS. Além disso, a instituição vem executando dois projetos: $O$ projeto Direitos Humanos e Saúde Mental em HIV/IDS, de Assessoria Jurídica e Psicológica e o projeto Campina Buddy, de acompanhamento domiciliar aos portadores.

O Projeto Direitos Humanos e Saúde Mental em HIV/AIDS disponibiliza um psicólogo e um advogado aos portadores de HIV/AIDS e a seus familiares, de terça a quinta-feira, no horário comercial, numa parceria com a Unesco e Programa Nacional de DST/AIDS do Ministério da Saúde. Tem por objetivo reduzir o impacto socioeconômico causado pela discriminação, preconceito e exclusão dos soropositivos e doentes de AIDS na sociedade, através da defesa dos direitos de cidadania.

O Projeto Campina Buddy de acompanhamento domiciliar é uma parceria da Comunidade Européia com duas ONGs do Rio de Janeiro (Grupo Pela Vida e o Grupo Arco-Irís), que fundaram aqui no Brasil a Rede Buddy Brasil - RBB sendo o GAV a única ONG do interior do País em sua composição. Buddy em português significa "companheiro" e foi um termo utilizado no início da década de 1980 na Europa voltado para identificar o acompanhamento domiciliar na casa das pessoas portadoras do vírus HIV. Há um treinamento no qual o Buddy, voluntariamente, compromete-se a visitar durante 8h/semana um cliente portador do vírus em seu domicilio, dando-lhe um apoio prático-emocional que pode ser alémdomicilio - na sessão de cinema ou na consulta médica. Atualmente o grupo conta com 50 clientes regularmente visitados por seus respectivos Buddies.

Outra atividade realizada chama-se Chát, a qual está dirigida aos portadores do HIV do grupo. O GAV tem no chát um momento de encontro e troca de informações sobre HIV/AIDS. Há também os eventos festivos, tais como as confraternizações juninas e de fim de ano. As palestras nas empresas ocorrem geralmente na Semana Interna de Prevenção de Acidentes de Trabalho - SIPATs. Já a Assessoria em Orientação Sexual - AOS é dirigida aos professores de ensino fundamental e médio, os quais recebem a visita dos técnicos para palestras e oficinas sobre a temática aids e sexualidade.

Procuramos conhecer as percepções dos técnicos a respeito de mudanças no funcionamento da instituição desde o seu ingresso, sendo apontadas as seguintes: redução do número de voluntários, priorização da execução de projetos, valorização do aspecto técnico do trabalho, redução dos recursos financeiros e diminuição da motivação dos profissionais.

Acerca de mudança de funcionamento da instituição desde o ingresso técnico, foram apontados os seguintes aspectos: redução de volutários, priorização da execução de projetos, valorização do aspecto técnico, redução dos recursos financeiros e diminuição da motivação dos técnicos.

Quando se lhes perguntou como avaliam essas mudanças, todos apontaram aspectos positivos e negativos. Dentre os aspectos positivos observamos a sistematização das atividades desenvolvidas, o incremento da atividade do técnico, o aumento da visibilidade social da instituição, a melhoria da qualidade das ações. Como aspectos negativos foram elencadas a diminuição do ativismo de rua, a diminuição do aspecto reivindicatório e propositivo da ONG, a restrição do financiamento dos projetos e a diminuição dos voluntários do grupo.

Um dos nossos objetivos foi investigar o conceito de ativismo presente entre os técnicos. Nesse sentido observamos diferentes concepções, desde as de cunho generalista até as mais específicas. Em primeiro lugar, ativismo aparece nas falas indicando ser uma luta ampla no sentido da participação social:
"Acho que ativismo é isso: é você ser um fiscal da sociedade para problemas que existem, que estão aí, que há uma deficiência do poder público em poder prestar esse serviço não só por parte do portador mas em qualquer setor da sociedade" (Batista).

A seguir observamos a concepção de ativismo agregando defesa de valores sociais, realização de tarefas, inserção em instâncias governamentais de controle social:

"É a gente estar ocupando os espaços. (...) agora
a gente saiu da rua para ir ocupar espaço no
Conselho de Saúde, no Conselho de... todos os
Conselhos que o GAV tem assento... Conselho
Tutelar, Conselho da criança e Adolescência,
Fórum Estadual, temos assento também no
Conselho Municipal de Assistência Social, no
Conselho de Psicologia; então, isso foi uma luta,
isso foi uma conquista do GAV; então o
ativismo mudou da maneira da rua para dentro
das instituições, os Conselhos e as lutas mesmo"
(Sofia).

Por fim, ativismo como uma prática diferente da militância:

"A militância, para mim, é aquela pessoa que está todo momento reivindicando seus direitos, lutando por uma ideologia, por uma 
mudança, por uma revolução; é aquela pessoa que a todo momento está antenado, está buscando essas alternativas. $\mathrm{O}$ ativista, não. $\mathrm{O}$ ativista ele é um pouco mais passivo. Ele apenas fica esperando que a demanda venha até ele e ele proponha alguma solução. Enquanto que o militante, não. Ele não espera que a demanda venha até ele. Ele vai até ela e tenta resolver o problema. Então... se a gente for falar de um modo geral, no meu entender há essa diferença entre o "militante" e o "ativista" (Pedro).

Enquanto a militância é a manifestação coletiva de comportamentos dirigidos à causa anti-aids visando a mudanças sociais e participação cidadã, o ativismo é a manifestação individual de um comportamento dirigido à causa visando a mudança pessoal e também coletiva:

"Tem pessoas que realmente desenvolve atividades no Grupo, quer que seja no GAV ou em qualquer outra ONG/AIDS no nosso País, que eles não estão atrelados a projetos, mas eles estão atrelados a ações dentro do próprio Grupo que se limita apenas ao ativismo, mas não a militância enquanto transformação social de um determinado grupo que você está beneficiando" (Bismarck).

Em função de tais concepções, as ações ativistas identificadas na instituição também foram muito variadas. Observamos ações como a busca pela visibilidade na mídia, a execução de projetos que oferecem assessoria jurídico-psicológica e o acompanhamento domiciliar, a realização de palestras em escolas e empresas, visitas ao fórum e delegacia de polícia e visita hospitalar.

\footnotetext{
"Ainda hoje, ainda vai reivindicar na mídia; a iniciativa que a gente faz na mídia é uma das ações ativistas que eu posso identificar". (Bartolomeu)

"então fazemos apenas o ativismo. $\mathrm{O}$ ativismo de desenvolver o projeto e atingir sua meta, e não aquele ativismo de tentar propor uma transformação social no públicoalvo que está sendo atendido pelo grupo; que é uma grande diferença”. (Bismarck)
}

A participação/representação nos mais diversos conselhos fiscalizadores e órgãos que compõem a sociedade civil responsáveis pelo controle social das ações governamentais também foi considerada uma ação ativista da instituição.

\begin{abstract}
"Porque a gente não pode mais só entender o ativismo como ligado só à temática aids, mas em qualquer espaço que a gente tem assento e que a gente possa fazer desse espaço político para ver a realidade da aids a gente está fazendo sim, ativismo. Então ativismo não é mais aquele só de.... ligadas a questões meramente aids, mas todos os espaços que o GAV tem assento que lá a gente consegue está cursando...um olhar para a aids. (...) A gente precisa avançar neste sentido. Então... nos conselhos, nos projetos... aonde a gente consegue estar participando enquanto luta é sim uma forma de ativismo" (Evangelina).
\end{abstract}

A maioria dos técnicos entrevistados considera que a entidade favorece a criação de estratégias de ativismo.

"Olha, desde que eu participo sempre favoreceu, e hoj,e por ter alguns projetos, poucas pessoas aqui na instituição sem ter condições de ir para rua mesmo, mas eu ainda acredito que a instituição, a vida orgânica do grupo favorece sim" (Wendell).

Apenas dois discordaram, argumentando que o envolvimento com o poder público interfere no controle social e que a redução da equipe inviabiliza a realização do trabalho.

"Eu acredito que não. A gente tem realmente ficado muito a desejar neste aspecto. É uma avaliação que eu faço e uma crítica ao mesmo tempo, porque a gente sempre está se deixando pela questão da parceria, do envolvimento que nós temos com o poder público, a gente está deixando muito desejar no aspecto realmente político de controle social". (Evangelina).

Dos pesquisados, um técnico acha que sua atividade não contribui para $\mathrm{o}$ fortalecimento do ativismo e os demais acreditam que sim, embora apenas um deles tenha enfatizado e problematizado a diferença entre ações ativistas e militantes. O que esse participante, especificamente, trouxe como diferença entre ações ativistas e militantes diz respeito às ações da ONG. Em sua opinião,

"O GAV atualmente não faz militância. Ele faz ativismo. E é um ativismo que eu poderia dizer, um ativismo nos moldes padronizados, globalizados. Esse tipo de ativismo que nós fazemos. (...) as ações dos projetos que são desenvolvidos aqui no grupo são ações ativistas, não militantes. (...) Então... 
desenvolvemos as metas de acordo com nossos órgãos financiadores e executores e pronto. Mas não há uma preocupação transcedente da gente ultrapassar essas barreiras e promover uma transformação social" (Bismarck)

Destarte as ações ativistas são dirigidas ao cumprimento de metas preestabelecidas da causa, e ações militantes canalizam a causa vinculando-a à necessidade de transformação social.

\section{DISCUSSÃO}

De acordo com os resultados anteriormente apresentados, alguns aspectos/categorias sobressaem em nossa análise: o funcionamento atual da ONG, a diversidade de concepções de ativismo presentes entre os participantes e, por último, uma indiferenciação entre ativismo e militância para a maioria dos técnicos.

Em relação ao primeiro aspecto, as mudanças observadas atualmente no funcionamento da ONG investigada refletem o contexto histórico de uma instituição inserida numa sociedade globalizada. De acordo com Gonh (1997), "entender o sentido das mudanças que estão ocorrendo no processo de desenvolvimento brasileiro dos anos 90 requer, em princípio, entender as transformações econômicas do país neste período e as novas ênfases em suas políticas sociais" (p.295).

As ONGs ou OSCs/AIDS integram o terceiro setor $^{5}$ em HIV/AIDS, e sua organização deveria implicar, segundo Fernandes (2004), "em uma certa complementaridade entre ações públicas e privadas". Entretanto, a literatura do campo indica que a "parceria" entre o Estado e o terceiro setor vem tendo a clara função ideológica de encobrir a reestruturação do

5 Segundo Montaño (2003), o termo Terceiro Setor foi introduzido no Brasil pela Fundação Roberto Marinho e foi cunhado nos EUA, em 1978, por Jonh Rockfeller. Portanto, têm nacionalidade, procedência e funcionalidade com os interesses de classe. O Terceiro Setor concentra ONGs, fundações, associações comunitárias, movimentos sociais. A discussão atual está voltada ao sentido de apontar que o crescimento desse setor é prova cabal do afastamento estatal da responsabilidade pelos serviços sociais e do bem-estar geral da população. O incremento do terceiro setor vem descolado de uma discussão acerca do processo de reestruturação produtiva do capital que oculta a desregulação dos direitos trabalhistas, encobre o esvaziamento dos direitos democráticos e legitima a extinção dos direitos sociais, trivializando as questões sociais, na medida em que sai paulatinamente da responsabilidade estatal e da ética, passando para a cotidianidade individual dos sujeitos na esfera da sociedade civil. capital globalizado, levando a população a um enfrentamento/aceitação deste processo que só vem servindo para a manutenção do sistema no sentido em que os isola da visão político-ideológica da realidade social, desistoricizando-a. Segundo Montaño (2003), o desenvolvimento do terceiro setor processou certos deslocamentos: lutas sociais para negociação/parceria; direitos por serviços sociais para atividade voluntáriofilantrópica; solidariedade social compulsória para solidariedade voluntária; do âmbito público para o privado; da ética para a moral e do universal/estrutural/permanente para o local/focalizado/fortuito.

A vigente e notável funcionalidade do terceiro setor, que movimentou, só nos Estados Unidos, U\$190 bilhões no ano de 1999, e que possuía no Brasil, no ano de 1995, 1,12 milhões de pessoas inseridas em ONGs, fundações, associações comunitárias e movimentos sociais, justifica e legitima a não-responsabilização do Estado pela intervenção social, desonera o capital da responsabilidade de co-financiar as políticas sociais, despolitiza os conflitos sociais dissipando-os, pulverizando-os e transformando-os em parceiros do Estado, fomenta desconfiança em torno da intervenção estatal e por fim reduz o impacto do aumento do desemprego (Montaño, 2003). Essa maquinação é fruto de uma modernidade neoliberal que agasalhou o capitalismo em sua nova égide ou máscara: o capitalismo neossocial-democrata.

Assim, nas sociedades contemporâneas, o terceiro setor passou a assumir um caráter mais profissional e menos caritativo e, por sua vez, as ONGs ou OSCs/AIDS passaram por um agrupamento que tem como base as atividades voluntárias desempenhadas, a imagem construída pela sociedade e o seu discurso oficial. Broncano e Galego (1994) dividiram os tipos de associação em conservadoras, moderadas, questionadoras e transformadoras. As conservadoras aceitam os valores dominantes, preservando $o$ estabelecido; as moderadas interpretam a realidade, mas não desejam mudar as estruturas; as questionadoras são propositivas e denuncistas e as transformadoras rompem com o estabelecido e propõem novos valores.

De acordo com isso, considera-se que a relação de "parceria" do movimento anti-aids com o Estado empurrou as entidades da sociedade civil a um dilema: são elas apenas executoras das políticas governamentais ou assumem o papel de propositores efetivos de políticas públicas? Se, de acordo com Montaño (2003) "com efeito, as ONGs passaram paulatinamente, na década anterior, a ocupar o lugar 
dos movimentos sociais deslocando-os de seu espaço de luta e da preferência da adesão popular" (p.271), ou seja se passam a ser o ator principal nesta relação, que conseqüências isso tem? Talvez implique em duas conseqüências diretas.

A primeira dessas conseqüências é o fato de que o movimento social das ONGs/AIDS, que representam os portadores do vírus HIV e os doentes de AIDS, intermediado pela própria $\mathrm{ONG}$, tende a se reduzir em quantidade e em impacto social em virtude da pouca adesão e da falta de recursos. A segunda, é que tais ONGs, agora parceiras do Estado, carregam as demandas populares, não mais numa relação de luta, mas de "pedido" e "negociação", assumindo a representatividade das organizações sociais (Montaño, 2003).

Dessa forma, entende-se que uma crise de identidade assolou as ONGs nacionais quando da execução do AIDS I e de sua continuidade com o AIDS II, em 1998. Reportando-se ao fato, Pelúcio (2002) ressalta que

O marco de transformação viria com o Projeto de Controle da AIDS-DST, o chamado AIDS I, financiado pelo Banco Mundial em 1992 e efetivado em 1994. Este muda de maneira significativa a estrutura do, então, Programa Nacional de DST/AIDS e altera as relações entre esta instância e as ONGs/AIDS (p.54)

No caso específico do GAV, seu perfil começou a sofrer transformações em 1998, quando foi assinado um convênio que garantiria financiamentos para a execução de dois projetos. A partir desse momento as relações entre a ONG e o Governo ficaram mais diplomáticas e assuntos antes tratados com veemência ganharam um viés mais cordial. Acompanhando os novos ares que caracterizavam os movimentos de forma ampla, o GAV passou, então, a desenvolver uma série de práticas dentro da lógica de "parceria", tais como o fortalecimento da participação nas câmaras técnicas e nos conselhos de saúde nos três níveis governamentais: municipal, estadual e federal. Os técnicos entenderam que deveriam consolidar esse novo modo de atuação, e questões que antes eram resolvidas através de mobilizações - tais como falta de medicamentos ou falta de leitos hospitalares - passaram a ser resolvidas através de reuniões entre representantes das ONGs nas câmaras técnicas com o Programa Nacional de AIDS ou nas instâncias dos programas estadual e municipal de AIDS.

Assim, observa-se que a ONG pesquisada também está atravessada no seu cotidiano pelos problemas da falta de adesão e desmobilização, na medida em que não vem conseguindo mobilizar técnicos e portadores para as atividades de rua, por exemplo. Eficiente na execução de projetos e em suas prestações de contas, o GAV não consegue dialogar minimamente sobre questões próprias e comuns aos portadores de HIV/IDS que congrega. Estes estão presos e absortos no emaranhado de burocracia em que se transformaram as ONGs em sua ânsia de executar projetos.

$\mathrm{O}$ segundo aspecto investigado diz respeito às diferentes concepções de ativismo presentes entre os técnicos. De uma forma geral, tais concepções apresentam-se como perspectivas pragmáticas, realização de tarefas. O novo formato da entidade, que diminuiu a atividade de rua para executar projetos, o envolvimento dos técnicos com a atenção aos portadores, dentre outras, é efeito de aspectos conjunturais, incluindo a política neoliberal e a revalorização social da aids, que ganhou o status de ser doença "crônica". Portanto, o ideário que perpassa tais concepções de ativismo é reflexo de um novo modus operandi que age a partir do momento em que os movimentos sociais e as ONGs no Brasil adentraram na era da globalização.

A globalização criou e fortaleceu a sociedade mundial de controle e sua influência sobre a produção de subjetividade. Nela há a captura da inteligência, da imaginação, da sensibilidade, da criatividade, da afetividade e da força dos trabalhadores assalariados. Para Pelbart (2003),

\begin{abstract}
O novo capitalismo em rede que enaltece as conexões, a movência, a fluidez, produz novas formas de exploração e de exclusão, novas elites e novas misérias, e sobretudo uma nova angústia - a do desligamento. (...) O que se vê então é uma expropriação das redes de vida da maioria da população pelo capital, por meio de mecanismos cuja inventividade e perversão parecem ilimitadas (p.21).
\end{abstract}

Sob esta ótica, o biopoder ${ }^{6}$ consolida-se como forma de assujeitamento. O poder sobre a vida se

\footnotetext{
Tomamos a noção de biopoder no sentido do "poder sobre a vida", que, segundo Pelbart (2003), surge no século XVIII e diz respeito à gestão da vida incidindo já não mais sobre os indivíduos (como no sistema disciplinar), mas sobre a população que passa a ser controlada, regulada em seus processos biológicos (tais como a reprodução, a natalidade, a mortalidade e o nível de saúde). Assim, o biopoder, ou poder de regulação da vida, administra o homem enquanto espécie viva nas cidades, na população, nas diversas instituições. Há uma diluição dos "muros" e o transbordamento da lógica de
} 
manifesta na difusão e na digestão de subjetividade. "Através dos fluxos de imagem de informação, de conhecimento e de serviços que acessamos constantemente, absorvemos maneiras de viver e sentidos de vida, consumimos toneladas de subjetividade" (Pelbart, 2003, p.20). O adestramento dos corpos, a disciplina vista como ascese e a submissão do corpo ao próprio corpo possuem direta ligação com as ações atuais das ONGs/aids. São os alicerces e os pilares das ações dos técnicos e destes sobre os usuários.

As ONGs exercitam o biopoder ao situar o técnico na prática da execução de projetos e do disciplinamento corporal do portador do vírus HIV, que deve necessariamente aderir ao coquetel, ao uso de preservativos, à vida orgânica da instituição. Considera-se que a ONG está visivelmente ancorada na concepção médico-jurídica da melhoria da qualidade biológica dos portadores do vírus HIV. Citando Foucault, Ortega (2004) afirma:

\begin{abstract}
Nossa sociedade atravessou o "umbral da modernidade biológica" na passagem do século XVIII para o XIX, quando o indivíduo e a espécie entraram nas estratégias e nos cálculos do poder político. A vida biológica e a saúde da nação tornaram-se alvos fundamentais de um poder sobre a vida (...). (p.10)
\end{abstract}

No que diz respeito à diferenciação entre ativismo e militância, ela foi apresentada na nossa pesquisa por apenas um dos técnicos. Pelúcio (2002), procurando deixar mais clara essa conceituação, reproduziu um trecho de entrevista realizada em 04/11/2001 com Cristina Câmara, ativista do Grupo Pela Vidda/RJ e ex-consultora do Programa Nacional de DST-AIDS, onde sustenta que

O ativismo se aproxima da militância nos
movimentos sociais, mas a centralidade no
indivíduo e o fato de ser marcado
simultaneamente por uma doença e um
handcap distanciam-os. A militância está
ligada diretamente a uma concepção de
esquerda que está supondo uma mudança na
sociedade (...) quanto ao ativismo, ele supõe

poder para outros setores da vida, fazendo-nos "prisioneiros a céu aberto" (Pelbart, 2000, p. 29). É nesse sentido que Deleuze (1992) sugere que os poderes sobre a vida encontram-se diluídos hoje na chamada "sociedade de controle", através do cruzamento entre a norma da disciplina e a norma da regulamentação (operada pelo biopoder), e em relação aos quais devemos responder com as "potências de criação da vida". um movimento extremamente pessoal (p.29$30)$.

Nosso pesquisado definiu militância como uma mobilização propositiva e reivindicatória que vai atrás da demanda. Estes resultados preliminares corroboram a concepção acima. Indicam que a concepção de ativismo presente entre os entrevistados, como dito anteriormente, refere-se à execução de projetos através das parcerias ONGs/órgãos financiadores, abrangendo a participação nos fóruns de discussões, sejam estes governamentais ou não. Militância, por sua vez, foi definida como ações que mobilizam os usuários dando visibilidade à causa anti-aids através de mobilizações de rua. Observou-se, portanto, diferença entre ativismo e militância, bem como a criação de estratégias de ativismo e não de militância na instituição pesquisada, pois executar projetos é uma ação ativista, mas não militante. Conseqüentemente observa-se que o GAV está mais "dócil” em sua relação com o capital e com o Estado; está despolitizado, esvaziado e imóvel, e isso quer dizer que o discurso comum em defesa da vida tornou-se uma armadilha neoliberal e capturou as ONGs, entre as quais se situa o GAV. Do mesmo modo que a relação ONG/capital/Estado sustenta-se no tripé da despolitização/esvaziamento/imobilismo, a indiferenciação apresentada pelos técnicos sustenta-se no tripé da docilidade/submissão/disciplina, na docilidade e passividade na relação técnico/ONG, na submissão aos ditames burocráticos da execução de projetos e disciplina enquanto discurso adotado pelo técnico. Ortega (2004) afirma:

O caráter sagrado da vida e a vitória do "animal laborans" na modernidade está vinculado ao processo de crescente despolitização, em que a vontade de agir transformou-se "na passividade mais mortal e estéril que a história jamais conheceu". Com isso a vida passa a ocupar o vazio deixado pela decomposição do âmbito público. Esse movimento da politização da vida - o que Foucault qualifica de biopoder - e que teve seu inicio nas sociedades ocidentais no século XIII, é para Arendt profundamente antipolítico (p. 10).

Destarte, o fato de a maioria dos técnicos tratar a questão da militância/ativismo de forma indiferenciada dá-se exatamente em função dessa recente configuração de parceria entre Estado e ONGs, que perpassa a execução de projetos e tem repercussão nas atividades de rua. Para a maioria dos técnicos essa configuração atual do ativismo suplanta a "militância".

$\mathrm{O}$ que o movimento anti-aids fez até agora foi fruto de militância ou de ativismo? O próprio 
movimento afirma-se como ativista, mas tudo nos leva a crer que militância e ativismo são dois lados da mesma moeda. Baltazar (2004) define militância como uma forma de participação política engajada e crítica, na qual são desenvolvidas ações voltadas para a conscientização política da população, buscando desenvolver novos valores que possibilitem às pessoas se organizarem e lutarem para a construção de uma sociedade justa e digna.

Militância pode ser definida também como a implicação do sujeito em determinada causa, que por sua vez vai produzir em si um conhecer militante capaz de uma ação militante. Merhy (2004) afirma:

\section{A produção deste saber militante é novo, e auto-analítico, individual e coletivo, particular e público. Opera sob vários modos de se ser sujeito produtor do processo em investigação e em última instância interroga os próprios sujeitos em suas ações protagonizadoras e os desafios de construírem novos sentidos para os seus modos de agir individual e coletivo (Merhy, 2004, online)}

O ativismo anti-aids é um estado consciente de mobilização e envolvimento coletivo ou institucional, dirigido à luta contra a aids, e é fruto de um movimento social. Para Galvão (2002, p.5), "desde meados da década de 90 está sendo cada vez mais premente o envolvimento da sociedade civil organizada e das pessoas com HIV/AIDS" em ações ativistas que envolvam manifestações de rua, reuniões com lideranças políticas, contatos com o parlamento, participação no Fórum de ONGs e atividades voltadas para a arte e a cultura.

Inevitavelmente, a luta institucional foi maquiada ao se aproximar do Estado, através das parcerias para execução de projetos. As ONGs deixaram de desejar luta para produzir resistência, e essa produção é a resistência do capital dissimulado e maquiado que as colocou numa perspectiva de mercado. Portanto, paradoxalmente, o momento atual da luta anti-aids se vê diante de uma pergunta: o desejo de luta contra a aids produziu as ONGs ou as ONGs produziram o desejo de luta?? A resposta é a própria luta travada na contemporaneidade.

A constituição do ativismo institucional na contemporaneidade é atravessada pelo capital da execução dos projetos. O movimento anti-aids atual tem o ativismo ou a militância que o capital permite: diminuição de atividades de rua, priorização da parceria Estado/ONG e representação nas câmaras técnicas de discussão. Por isso o dilema spinozano é adequado às ONGs e ao GAV: "Por que os homens lutam por sua opressão como se se tratasse de sua liberdade"?(Spinoza, 1670).

\section{CONSIDERAÇÕES FINAIS}

Atuar contra a aids, institucionalmente, na sociedade civil, significava brigar por mais leitos em hospitais, por políticas públicas em HIV/AIDS e fazer visitas domiciliares e hospitalares às pessoas que vivem e convivem com a doença; mas esse cenário de luta mudou entre o final da década de 1980 e inicio dos anos 1990, com a consolidação das políticas públicas em HIV/AIDS e a descoberta da medicação especifica para os portadores do HIV, o chamado coquetel ${ }^{7}$.

Desde então ativismo contra a aids passou a significar execução de projetos de intervenção comportamental, projetos de assessoria jurídica e de saúde mental, orientação e monitoramento do cumprimento das diretrizes de políticas públicas em HIV/AIDS referentes à assistência e tratamento e o fomento à participação nos fóruns estaduais e nacionais de discussões sobre a temática.

Concluindo, o resultado da pesquisa indica que, embora a nova forma de ativismo esteja consubstanciada na execução de projetos e na inserção da ONG nos órgãos de representação e controle social, a atividade de rua e de mobilização social precisa ser resgatada. Sua redução atingiu em cheio o caráter voluntário das ONGs e, conseqüentemente, houve um desmantelo em seu staff de trabalho.

As entidades precisam refletir sobre como transformar uma situação imobilista de execução de projetos, que torna a ONG uma instituição conservadora e funcionalista, em uma organização transformadora, que possa levantar novos propósitos e mobilizar portadores do HIV/AIDS e a sociedade civil para a intervenção na arena política. Só assim será possível às ONGs escaparem da perspectiva de mercado, da superficialidade, da não-singularização e da homogeneidade.

\section{REFERÊNCIAS}

Baltazar, B. (2004). Os encontros e desencontros da militância e da vida cotidiana. Psicologia: Teoria e Pesquisa, 20(2),183-190.

\footnotetext{
Coquetel: Conjunto de medicamentos que interagem entre si e atuam impedindo multiplicação do vírus HIV. Conhecidos também por antiretrovirais.
} 
Broncano, M. C. \& Gallego, J. C. (1994, Jan./Mar). ¿Por dónde anda hoy el Asociacionismo en Andalucía? Documentación Social. Revista de Estúdios Sociales y de Sociologia Aplicada, , 157-76.

Câmara, C. \& Lima R. (2000). Histórico das ONGs/Aids e sua contribuição no Campo das Lutas Sociais. Em Cadernos ABONG (Org.), Direitos humanos, cidadania e Aids, 28, p.40. São Paulo: Ed. Autores Associados.

Castilho, E. (1997). “É necessário entender a aids”: notas da rede Brasília: Coordenação Nacional de DST e AIDS/ Ministério da Saúde.

Deleuze, G. (1992) Conversações. Rio de Janeiro: Editora 34.

Fernandes, R. C. (2004). O que é o terceiro setor. Disponível em <http://www.rits.org.br>. (Acessado em 09/06/2004).

Galvão, J. (2000). Aids no Brasil: a agenda de construção de uma epidemia. São Paulo: Editora 34.

Galvão, J. (2002). A política brasileira de distribuição e produção de medicamentos anti-retrovirais: privilégio ou um direito? Cadernos de. Saúde Pública, 18(1),213-219.

Gonh, M. G. (1997). Teorias dos movimentos sociais: paradigmas clássicos e contemporâneos. São Paulo: Loyola.

Merhy, E. (2004). Saber militante e implicação do trabalhador. Disponível em <http://www.paginas.terra.com.br/saude/merhy> (Acesso em 22/12/2005).

Montaño, C. (2003). Terceiro setor e questão social: crítica ao padrão emergente de intervenção social. São Paulo: Cortez.
Ortega, F. (2004). Biopolíticas da saúde:reflexões a partir de Michel Foucault, Agnes Heller e Hannah Arendt. Revista Interface-Comunicação, Saúde, Educação. 8, 9-20.

Pelbart, P. P. (2000). A vertigem por um fio: políticas da subjetividade contemporânea. São Paulo: Iluminuras.

Pelbart, P. P. (2003). Vida capital: ensaios de biopolítica. São Paulo: Iluminuras.

Pelúcio, L. (2002). ONGs/AIDS e Estado: parceria e conflito. Dissertação de Mestrado Não-Publicada, Programa de PósGraduação em Sociologia Política, Universidade Federal de São Carlos, São Paulo.

Spink, M. J. P. (2000, $2^{\text {a }}$ ed.). Práticas discursivas e produção de sentidos no cotidiano: aproximações teóricas $e$ metodológicas. São Paulo: Cortez.

Spink, M. J. P. \& Lima, H. (2000). Rigor e visibilidade: a explicitação dos passos de interpretação. Em M. J. P. Spink (Org.), Práticas discursivas e produção de sentidos no cotidiano: aproximações teóricas e metodológicas (pp. 93122). São Paulo: Cortez.

Terto Junior, V. (2004). A sociedade civil e os desafios na terceira década da AIDS. Disponível em <http://www.abiaids.com.br>. (Acesso em 09/06/2004).

Recebido em 23/06/2005 Aceito em 03/02/2006

Endereço para correspondência: Magda Dimenstein. UFRN-CCHLA/Dept ${ }^{\circ}$ de Psicologia, sala 610, Campus Universitário, CEP 59.078-970, Natal-RN. E-mail:magdad@uol.com.br 